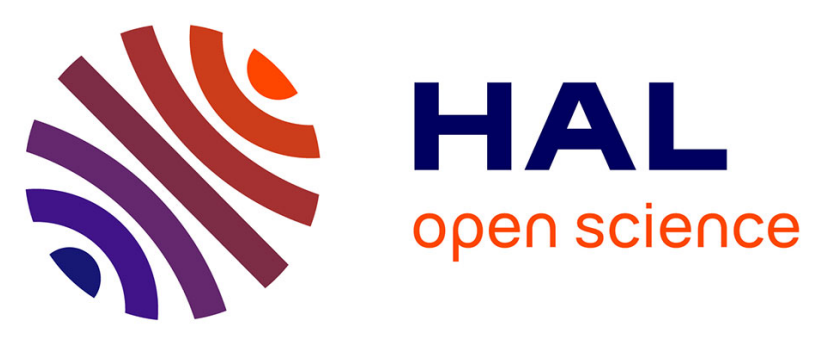

\title{
Qualia and Representations
}

Elisabeth Pacherie

\section{To cite this version:}

Elisabeth Pacherie. Qualia and Representations. Denis Fisette. Consciousness and Intentionality: Models and Modalities of Attribution, Dortrecht, Kluwer Academic Publishers, pp.171-206, 1999. ijn_00000244

\section{HAL Id: ijn_00000244 \\ https://hal.science/ijn_00000244}

Submitted on 28 Oct 2002

HAL is a multi-disciplinary open access archive for the deposit and dissemination of scientific research documents, whether they are published or not. The documents may come from teaching and research institutions in France or abroad, or from public or private research centers.
L'archive ouverte pluridisciplinaire HAL, est destinée au dépôt et à la diffusion de documents scientifiques de niveau recherche, publiés ou non, émanant des établissements d'enseignement et de recherche français ou étrangers, des laboratoires publics ou privés. 
Pacherie, E. Qualia and Representations. In in D. Fisette (ed.) Consciousness and Intentionality: Models and Modalities of Attribution, Dortrecht, Kluwer Academic Publishers, pp. 171-206.

\title{
QUALIA AND REPRESENTATIONS1
}

\author{
Elisabeth Pacherie \\ pacherie@ehess.fr
}

\begin{abstract}
Dretske has recently offered a representational theory of perceptual experience considered as paradigmatic of the qualitative and phenomenal aspects of our mental life. This theory belongs, as do his previous works, to a naturalistic approach to mental representation.

I would like to highlight some difficulties that arise when this representational approach is extended to certain qualitative aspects of the mental. First, I give a general outline of Dretske's representationalist strategy, mentioning along the way certain modifications or novelties in his use of distinctions he had previously drawn. I then focus on three aspects of his theory that seem to me to involve potential problems or inconsistencies. I first concentrate on the way Dretske uses his distinction between firstorder consciousness and second-order consciousness in his account of the phenomenon of blindsight. My second concern is with the problem of qualia inversion - the theoretical possibility of which Dretske acknowledges - and his treatment of it in representational terms. Lastly, I criticize Dretske's idea that the qualitative differences between perceptual experiences in different modalities always reduce to differences in the sensory properties the perceived scene or object is represented as having or to differences in the conceptual elaborations based on those properties. I suggest that we can get a more accurate insight into the nature of these modality-related differences if we examine their potential relations with, on the one hand, the role or function of consciousness in perception and with, on the other hand, that special character of the relation to the object in perception that Husserl described as 'Leibhaftigkeit'.
\end{abstract}

\section{Résumé}

Dretske a récemment proposé une théorie représentationnelle de l'expérience perceptive - considérée comme manifestation paradigmatique des aspects qualitatifs et phénoménaux de notre vie mentale. Cette théorie s'inscrit, comme ses travaux antérieurs, dans le cadre d'une approche naturaliste des représentations mentales.

Je souhaiterais mettre en évidence certaines difficultés que pose l'extension de cette approche aux aspects qualitatifs du mental. Je présente d'abord dans ses grandes lignes la stratégie représentationnaliste de Dretske et indique au passage certains infléchissements ou usages nouveaux de distinctions qu'il avait antérieurement élaborées. Je me concentre ensuite sur trois aspects de sa théorie qui me semblent problématiques. Il s'agit, premièrement, de l'application que fait Dretske de la distinction entre deux ordres de conscience dans son analyse du phénomène du

\footnotetext{
${ }^{1}$ My thanks to Roberto Casati, François Clémentz, Denis Fisette, Pierre Jacob, Pierre Livet, Claude Panaccio, and Joëlle Proust for their comments and suggestions.
} 
blindsight. Il s'agit, deuxièmement, du problème des inversions qualitatives, dont il admet la possibilité, et du traitement qu'il en propose en termes représentationnels. Enfin, je critique l'idée de Dretske selon laquelle les différences qualitatives entre expériences perceptives associées à des modalités sensorielles distinctes ne sont jamais imputables à la seule différence des modalités prise en elle-même mais sont toujours liées soit à des différences concernant les propriétés sensorielles représentées soit à des différences d'exploitation conceptuelle. A cette occasion, j'essaie d'indiquer certains liens possibles entre la fonction de la conscience perceptive, la distinction des modalités et ce caractère spécifique du rapport à l'objet dans la perception, que Husserl désignait du nom de 'Leibhaftigkeit'.

Philosophical attitudes towards qualia divide into three main types. First, there are qualia enthousiasts who claim that qualia exist and do not reduce to anything else. These philosophers also typically consider that the existence of qualia is sufficient to doom physicalist or functionalist approaches to the mind. Supporters of qualia elimination are to be found at the opposite end of the spectrum. They deny that mental states and events actually possess the qualitative properties attributed to them by qualia friends and, as a consequence, they advocate quining qualia. In between these two extreme positions stand the advocates of demystification. They admit the existence of qualia but they try to dissipate the air of mystery that surrounds them by showing that they can be accounted for in functional or representational terms.

Dretske belongs to this last category. In his Jean Nicod lectures (Dretske, 1995), he offers a through defense of the representational thesis that "all mental facts are representational facts". In these lectures, he concentrates on the mental facts that seem most refractory to a representational approach, namely facts concerning the subjective aspects of mental life, to be found in particular in perceptual experience. This theory of the subjective elements of mental life is meant as an extension of Dretske's previous works on intentionality and perception and it makes use of distinctions elaborated in those works. It seems to me, however, that the treatment Dretske proposes of some phenomena concerning qualitative aspects of our mental life is less than satisfactory. In particular, it is the case with his treatment of the problem of blindsight, with his treatment of the problem of qualia inversion, and finally with his account of the possible nature of the qualitative differences among perceptual experiences in different sensory modalities.

In the present paper, I shall concentrate on the theory offered by Dretske (1995) in order to account for the qualitative aspects of perceptual experience, i. e. for the way things appear to us in perception. This theory is based on a theory of representation and on a theory of introspective knowledge. The first section gives a general outline of Dretske's representational strategy as it applies to perceptual experience. In section II, Dretske's theory of introspective knowledge is examined and the issue of the relationship between perceptual experience and consciousness is discussed, in particular with regards to the problem of blindsight. Sections III and IV examine the way in which Dretske conceives of the possible differences between qualitative experiences. Section III is concerned with the problem of qualitative inversions. Section IV discusses the problem of the distinctions among qualitative experiences in different modalities. In this fourth section, I attempt to point out a number of possible links between the function of perceptual awareness, the distinction among sensory modalities, and the special 
character of the relation to the object in perception that Husserl described as 'Leibhaftigkeit' or 'bodily presence'.

I

According to Dretske's 'Representational Thesis', all mental facts are representational facts. From this thesis it follows that the qualities of perceptual experiences must be constituted by the properties things are represented as having. By a representational fact, Dretske means a fact about a representational system or state as representational, in other words, it is a fact about what information the system or state is supposed to carry. Representational facts constitute a subset of facts about representations. The latter are not necessarily facts about representations as representations; for instance, they can be facts about physical features of representations that have no direct link to their representational content.

Dretske contends that perceptual experience constitutes a type of natural, nonconceptual representation. The notion of representation he makes use of is the notion he had defined in Explaining Behaviour (1988). It combines informational ideas - with the notion of indication - and teleological ideas - with the notion of a function of indicating. Very crudely then, a representation is a thing whose function is to carry information. In the theory of representations Dretske proposes, three distinctions play a pivotal role. The first distinction is between natural vs. conventional representations. When of a thing's information-providing function is derived from the intentions and purposes of its designers, makers or users, the resulting representations are conventional. By constrast, natural representations do not owe their informational function to the intentions or purposes of external designers. According to Dretske, perceptual representations are natural representations: the senses have information-providing functions, biological functions, that they derive from their evolutionary history. The perceptual systems produce representations of those conditions they have the function of informing us about.

However, perceptual representations must be distinguished from other types of natural representations, such as beliefs and thoughts. Whereas the latter are conceptual representations, the former are sensory and not conceptual representations. This distinction between sensory and conceptual representations rests, according to Dretske, on a distinction between the possible sources of the information-providing functions of a (token) representational state. A state can derive its function from the system of which it is a state, in which case it has a systemic indicator function and hence gives rise to a systemic representation (representation ${ }_{\mathrm{S}}$ ). Or, a token state may acquire its indicator function, not from the system of which it is a state, but from the type of state of which it is a token (representation $n_{a}$ ). Functions of this latter type are acquired indicator functions and they are independent of the systemic indicator function that the state types may also have.

Dretske proposes that we identify perceptual experiences with states whose representational properties are systemic and that thoughts and conceptual representations in general be identified with states whose representational properties are acquired. More precisely, Dretske conceives of the relationship between perceptual experience and conceptual thought in the following way: "Experiences are those natural representationss that service the construction of representations $\mathbf{a}$, representations a that can be calibrated (by learning) to more effectively service an organism's needs and desires. They are the states whose functions it is to supply information to a cognitive system for calibration and use in the control and regulation of behavior" (1995: 19). 
It is important here to distinguish clearly between two different, although complementary, senses in which it is possible to say that a state has a function. On the one hand, a given state can have an informational or indicator function; on the other hand, this same state has a role to play in the economy of a cognitive system, it has what could be called an organizational function. To take a favorite example of Dretske's, a thermostat has a representational function insofar as its function is to carry information about temperature in the environment. But considered, for instance, as an element in a central heating system, it has also an organizational function: its function in this sense is to control the furnace ignition. As for sensory representations, their representational function is to carry information about certain phenomenal properties in the environment of the system to which they belong. Their organizational function is to supply this information to the rest of the cognitive system. There exists an important link between the two functions. 2 The acquisition 3 by a state type of a representational status goes hand in hand with the acquisition of an organizational or control job in the system. The tokens of the state type may - and should - have indicator properties before being recruited for a control job, but it is only by being thus recruited that they acquire an indicator function. In the case of representations that are the outcome of natural selection, as is the case, according to Dretske, of sensory representations, the story is the following. Evolution has conferred tokens of a given state type in a given species the function of carrying information about the presence of, say, $F$ s, because in the past, in certain members of the species such tokens carried information about the presence of $F \mathrm{~s}$ and happened to play a role in the control of certain behaviors the success of which depended on the presence of $F$ s. This does not mean that a given indicator function and a given control duty are for ever associated. A state type can acquire new control duties without losing its representational function or, in some cases, it can change its representational function without changing its control duty, but the establishing of a representational function requires the simutaneous establishing of an organizational function.

Finally, it should be noted that sensory systems have, according to Dretske, phylogenetic functions and are, therefore, comparatively modular. Hence, systemic sensory representations are fixed. This does not mean that our perceptual experiences are immune to change through time, but it means that such changes are the result not of a modification of the systemic sensory representations but of the addition of one or several new layers of acquired representations. The qualitative aspects of our representational experiences are thus, for Dretske, phylogenetically determined. The subjective quality of an experience, what it is like to have this experience, is simply the way this experience represents $s_{\mathrm{s}}$ things to be.

\section{II}

I now want to examine Dretske's view of the relationship between qualia thus conceived and consciousness and the application he makes of his conception in the account he suggests of the phenomenon of blindsight. I shall start with some clarifications concerning Dretske's terminology. Dretske (1995: 97 sq) protests againts

\footnotetext{
2 In particular, this link plays an essential role in Dretske's account of the causal efficacy of mental content. However, I will not discuss here the issue of the causal efficacy of mental contents, since it seems that, for Dretske, only acquired representations can properly be said to have a causal efficacy in virtue of their contents and since the sensory representations I am concerned with are, according to him, systemic and not acquired.

3 "Acquisition" should be taken here in a broad sense covering both acquisition by an individual in the course of learning and acquisition by a species in the course of evolution.
} 
what he takes to be a common misunderstanding of the distinction between two uses of the term "conscious". The first, transitive, use corresponds to the application we make of the word conscious when we say of a being that he is conscious of something. It corresponds to what Rosenthal (1990) calls creature consciousness. This sense is to be distinguished from the use one makes of the word when one says of a state or process that it is conscious. This second use corresponds to what Rosenthal calls state consciousness and it it intransitive in the sense that saying of a state that it is conscious is not saying that the state is conscious of something. However - and this is the misunderstanding Dretske wants to expose - , when we attribute consciousness to a state, an experience or a process in this intransitive sense, we are not, by the same token, attributing this state, experience or process an intrinsic property. The difference between a conscious and an unconsicous experience (or state, or process) is not, according to Dretske, a difference in the experience, it is a difference in the experiencer (the owner of the state or process).

Thus, granted that when Dretske speaks of a conscious experience he does not intend to attribute to this experience a real, non-relational property that would distinguish it from unconscious experiences, there nevertheless remain two things he may want to say. First, he may want to say that the creature who has an experience is conscious of the object or property of which this experience constitutes a sensory representation. For instance, if I hear the sound of a French horn and thus have an auditory experience of a French horn, one may say that I have a conscious experience of the French Horn, in the sense that I am aware of an auditory event, but this does not require the bringing into play of conceptual abilities - I don't need to have the concept of a French horn - or the bringing into play of metarepresentational capacities - I don't need to represent my auditory experience as an experience. This is a sense of 'conscious experience' Dretske explicitely endorses, when he claims that conscious states are states that "make one conscious of whatever properties the representation is a representation of and, if there is such, whatever objects [...] these properties are properties of' (1995: 104). The second possibility is that by 'conscious experience' one means an experience such that the creature who is having this experience is conscious of having the experience, that it has a representation of this experience as an experience. In the ensuing discussion, I shall speak of consciousness 1 when referring to a conscious experience in the first sense, and of consciousness 2 when referring to a conscious experience in the second sense.

Given the way Dretske defines perceptual experience - namely in purely representational terms - it would seem that all perceptual experience is by definition conscious 1 since an experience is a systemic sensory representation of an object (or a state of affairs) and since the qualitative properties of the experience are identified by Dretske to the phenomenal properties that the object or state of affairs is represented as having. However, we should avoid as much as possible making the notion of consciousness 1 too trivial. It is not enough that a state be representational in order for it to be conscious1. Probably, Dretske would want to distinguish between a representational state that is merely present in an organism and a representational state that is present for the organism. If we consider, for instance, Marr's theory of vision, we are not conscious 1 of the primal sketch, not because it is not a representational state, but because the information contained in this state is not available to the system as a whole for further elaboration and use in the control and regulation of behavior. One may nevertheless regret that Dretske does not give us any specific account of the conditions that must be satisfied for a system to count as conscious1. I am not conscious 1 of the primal sketches worked out by my perceptual modules. But should I accept that the modules themselves are conscious 1 of the representational contents of the primal 
sketches since they make use of them in order to construct more elaborate representations? Thus, there remain in Dretske's approach unresolved difficulties concerning (1) the conditions that must obtain in order for a state to be considered as present for the system and not merely in the system, and (2) the conditions that must obtain for a system to count as conscious1. These difficulties being noted, one may say that a creature satisfying the conditions to be spelled out in (2) and having representations satisfying the conditions to be spelled out in (1) would be conscious 1 , in the sense that it would be aware of the objects that these representational states are representations of?

What about consciousness2? What can it consist in given Dretske's representational theory of experience? Dretske claims to be defending a cautious approach to qualia that operates with a minimal conception of them. In particular, Dretske refuses to burden himself from the start with a characterisation of qualia that includes the features cataloged and questioned by Dennett (1988)4 He nevertheless considers, in agreement with Shoemaker (1991), that even a minimal characterisation of qualia should include accessibility to consciousness, by which he clearly means consciousness 2 , the capacity that a creature has to represent introspectively to itself its experiences as such. This accessibility to consciousness thesis can be given a stronger or a weaker reading. Before I examine the reasons one can offer in favor of one or the other of these readings, I give a more precise description of what the fact for an experience to be conscious 2 can consist in given Dretske's representational thesis.

Dretske holds that the awareness we may have of our perceptual experiences constitutes a particular instance of introspective knowledge. Introspective knowledge in general is the knowledge of representational facts about our mental representations. It consists in metarepresentations, that is to say, according to Perner's (1991) definition, in the representation of representations as representations. Conscious2 perceptual experience is thus introspective knowledge of our systemic sensory representations as representations. But how do we come by such knowledge, how can we know our mental representations as representations?

According to Dretske's account, introspective knowledge is an instance of displaced perception and can be described as a knowledge of internal facts via an awareness of external objects. Dretske gives several examples of displaced perception. One listens for the sound of a timer to find out when the cake in the oven is done, one learns that too much sugar consumption endangers one's health by reading the newspapers and one realizes that one should have resisted treating oneself without restraint to chocolate cake when one sees the position of the needle on the bathroom scale. As Dretske puts it: "In such cases one comes to know that $k$ is $F$ - sees that $k$ is $F$ - by seeing and hearing not $k$ itself but $h$. The perceptual fact is displaced from the perceptual object" (1995: 41). Perceptual displacement occurs when there there is conceptual but no corresponding sensory representation of an object. The chocolate addict who sees by looking at his bathroom scale that he has gained weight has a sensory representation of the scale and of some of its properties (its color, shape, size, orientation, etc.) but he has a conceptual representation of himself has having gained superfluous weight.

The existence of displaced perception requires that the subject believes in the existence of an appropriate link between the properties of the sensuously represented object and the properties of the conceptually represented object. Dretke's suggestion is

4 According to Dennett (1988), qualia are traditionally taken to have the following four fundamental properties: they are supposed to be ineffable, intrinsic, private, and directly or immediately apprehensible to consciousness. 
that we consider introspective knowledge as being both an instance of metarepresentation and an instance of displaced perception. Introspective knowledge thus consists in a representation of a representation $(k)$ as a representation $(F)$. It is moreover an instance of displaced perception insofar as we have a conceptual representation of $k$ as being $F$ by having a sensory representation of some other object $h$ as being $G$. Dretske's thesis is that the $h$ s and $G$ s are none other than the objects and properties already present in the representation subjected to introspection. According to the example he takes, if $E$ is an experience of blue, then introspective knowledge of this experience is a conceptual representation of it as an experience of blue and we have a conceptual representation of $E$ as a representation of blue by having a sensory representation of the object that the experience $E$ represents as blue.

According to Dretske, every representational system carries information on the way it represents the world to be. A system representing the world necessarily occupies a state that carries information on how the world would be if the system was functioning properly and it is the representational state it is in that carries this information. This is what constitutes the fundamental asymmetry between the situation of an external observer and that of a system introspecting its own states. The external observer does not occupy the state whose representational content he is investigating. Thus, he is forced to attend both to the states of the representational system he investigates and to the states of the world in order to determine what the contents of the system's states are. By contrast, the privilege of introspection consists in the fact that the representational system itself can occupy the states that are being investigated. He thus has available to himself information to which no other system has a direct access, namely information on how the world would be if it was functioning properly as a representational system.

According to Dretske, this informational privilege is shared by all representational systems, but this does not mean that all representational systems are capable of introspection. Every representational system, in representing the world, has all the information it needs to know how it is representing the world, but for it to have self knowledge it must also be able to exploit this information. This requires metarepresentational capacities that a large number of representational systems lack. For a system to be capable of introspective knowledge, it is further required that it have the conceptual resources for representing the fact to be known and an appropriate 'connecting belief' about the relationship between the information it gets by perceiving the external world and the facts concerning its own representational states.

After these clarifications, we can come back to the thesis that qualia must be accessible to consciousness. One can give this thesis a strong ontological reading and take it as claiming that it is constitutive of qualia and hence of perceptual experience to be accessible to consciousness. Or, to put it in negative terms, this means that something that is not in principle accessible to consciousness cannot be a quale. But such an interpretation seems to be stronger than what Dretske would want to claim, since he admits that animals that lack metarepresentational capacities or young children who have not yet developed those capacities nevertheless have conscious 1 qualitative experiences. Actually, Dretske attribute this strong interpretation of the accessibility thesis to the advocates of higher-order theories of state consciousness, such as Armstrong (1980) and he rejects such theories precisely because they force one to deny that animals and young children can have conscious experiences.

A weaker reading of this accessibility thesis limits its scope to creatures endowed with metarepresentational capacities: qualia are among the states that a creature endowed with metarepresentational capacities could in principle have conscious access to. Interpreted in this way, the thesis imposes a constraint on a theory of qualia: a theory of the nature of qualia cannot be satisfactory if it does not account for the possibility that 
qualia be the objects of introspective knowledge in creatures endowed with the necessary introspective capacities. But Dretske tells us that his theory of qualia can satisfy this constraint since it claims (1) that to be capable of introspective knowledge is to have the metarepresentational capacity to represent its representations as representations, and (2) that qualia are but a special variety of representational states. However, a large part of what goes on in the mind, including a large number of representations, is not accessible to consciousness 5 Hence, one might yet wonder why a creature with metarepresentational capacities should apply those capacities to its perceptual experiences.

It is possible to answer this question by giving the accessibility thesis a Darwinian interpretation. This is an approach taken by Shoemaker (1991). Roughly, the reasoning is the following. Creatures that are the outcome of natural selection would not have developed metarepresentational capacities unless those capacities had positive consequences for the survival and reproduction of those creatures. It is likely that the major advantage conferred by such capacities is to make possible the attribution to oneself and to others of mental states, and thus to allow for the prediction of future behavior. This serves as a basis for the development of a richer pattern of social interactions between conspecifics which in turn increases the chances of survival and reproduction of the members of the species. But the success of such cooperative interactions depends not only on the ability individuals have of conveying their intentions; it depends also on their ability to communicate what their reasons are for having those intentions. Those reasons will include the reasons they have for the beliefs that justify their intentions 6 This is where, according to Shoemaker, access to sense experience comes in: "In forming beliefs based on sense-perception, one will be handicapped if one does not have the ability to be aware of how things look, sound, feel, etc., to one, and so is not in a position to consider whether conditions are such that things looking (sounding, etc.) that way to one is a good reason for thinking that they are that way" (1991: 515).

Although Dretske is in agreement with Shoemaker when he insists that qualia must be accessible to consciousness, his remarks on the problem of blindsight suggest that he does not completely share Shoemaker's views. One should note, first, that Shoemaker wants to maintain a distinction between the intentional properties of our perceptual experiences and the phenomenal, non-intentional properties of these experiences that he identifies with qualia. By constrast, as we have seen, Dretske rejects this distinction and claims that qualia are nothing but sensory representational properties of our perceptual experiences. Although this is a major disagreement, this is not their fundamental point of divergence as far, at least, as the problem of blindsight is concerned.

Shoemaker's Darwinian argument on the usefulness of the accessibility to consciousness of qualia clearly involves consciousness2. It is relatively easy to extrapolate his view on blindsight in human beings from what he says on the possibility that the bat's echolocation be 'blindsighted'. Shoemaker (1991) assumes it to be a fact that bats have little or nothing in the way of introspective access to their internal states. He thinks that bats nevertheless have innate quality spaces, that there is some similarity

\footnotetext{
5 In particular, this is the case with the intermediary representations computed by the linguistic or sensory modules, such as, for instance, the primal sketches in Marr's theory of vision or the deep syntactic representations of sentences in a Chomskian conception of a linguistic module.

6 The argument offered by Shoemaker constitutes a "social" version of a Darwinian justification of the existence of phenomenal experience. But it is also possible to give the Darwinian justification a more "indivualistic" flavour, by claiming for instance that conscious control of one's actions as opposed to their automatic control brings with it the benefit of flexibility. This is, in particular, the line of reasoning taken by Weizkrantz (1988).
} 
ordering of the sensory states produced by the stimuli available to them. He claims that it is in virtue of these similarity relations that these sensory states have properties that corresponds to some of the roles played by qualia. In other words, qualia as types are functionally individuated by their identity and similarity conditions. Insofar as, in the case of bats, these states are not accessible to consciousness, since it is assumed that bats have little or no introspective capacities, Shoemaker speaks of 'quasi-qualia'. Given those views, it seems reasonable to assume that Shoemaker would describe the phenomenon of blindsight as a situation in which a creature has visual quasi-qualia, but has no introspective access to them. To put it otherwise, blindsighters have sensory states endowed with qualitative properties, but they have no conscious access to the qualitative properties of those states. Insofar as certain 'beliefs 7 are more or less automatically formed on the basis of the information conveyed by these sensory states, the blindsighters have those beliefs, but lacking a conscious access to qualia, they can offer no justification for them.

By constrast, Dretske takes blindsight to be a problem related to consciousness 1 and not consciousness2. What blindsighters lack, according to him, is visual experience: these people have no sensory representations of the objects and properties visually presented to them. They are not visually conscious 1 of these objects. But the analysis Dretske offers of blindsight seems hardly compatible with some of the other views he holds. Dretske accepts that, although lacking visual experience, blindsighters have nevertheless access to at least part of the information normally conveyed through visual experience, since they are capable, in certain conditions, of taking appropriate action towards objects, and that their statistically significant performance towards those objects would not be explainable unless it was assumed that they have this information. 8 Dretske suggests that blindsighters have no visual experience of the present situation but that they nevertheless process part of the conceptual representations that are necessary for the control and guidance of deliberate intentional action, and that, in normal subjects, are formed on the basis of conscious visual experience. Dretske acknowledges that those facts are puzzling . But, to my mind, they are more then just puzzling, they contradict Dretske's account of consciousness.

Recall that, according to Dretske's representational theory, a visual experience is but a sensory experience of an object or a situation and that sensory representations are states whose organizational function it is to supply information to a cognitive system for the construction of conceptual representations that can be used in the control and regulation of behavior. Conversely, conceptual representations are built from sensory

\footnotetext{
7 Here the term 'beliefs' serves to designate the representations formed on the basis of visual information and used for the guidance of certain actions. That such representations are indeed formed seems to be demonstrated by the fact that blindsighters are capable (when forced) to take appropriate action towards objects visually presented to them and that the success of their performance can only be explained if we accept that they have formed those representations. See the next footnote for examples of such actions. A number of philosophers will claim that other conditions must be satisfied as well for a representation to be a belief in the full sense of the term. They are certainly right and this is why I use quotes. Let us note however that those 'beliefs' share a number of properties with fully fledged beliefs: their are representations of states of the world, they involve if not conceptualization in a strong sense at least a certain categorization or digitalization of sensory information and, most importantly, they guide action.

${ }^{8}$ For instance, blindsighters asked to reach out for an object presented in their blind visual field and that they deny seeing — are nevertheless able to reach for it accurately and to adopt a hand shape appropriate to the object presented. Or, placed in forced-choice situations, they are able to 'guess' quite accurately for the presence or the absence of an object, to guess whether the object presented is a horizontal or a vertical bar, whether it is moving or not, whether they are presented with an X or an O, and so on. For more details, see Weizkrantz (1986, 1988), Marcel (1988), Young \& de Haan (1993).
} 
representations. In particular, epistemic perception constitutes a case of displaced perception: we acquire a conceptual perceptual representation by having a sensory representation. Furthermore, according to Dretske's representational theory of qualia, a system that has a sensory representation is by definition conscious 1 of what his representation is a representation of, provided that the sensory representation in question be a representation for the system and not merely in the system. A sensory representation is a representation for the system, if the system can exploit it for the construction of conceptual representation, and hence for the control and regulation of behavior.

We are now in a position to better appreciate Dretske's uncomfortable situation. Dretske acknowledges that it is necessary to attribute to blindsighters certain conceptual representations about the objects they say they are not visually aware of, in order to explain the appropriateness of their actions towards those objects. Dretske also claims that conceptual representations are built from sensory representations. As a result, he is forbidden by his theory to attribute conceptual representations to those individuals without at the the same time attributing them the sensory representations that are necessary for their construction. But, insofar as he also contends that having qualitative experiences or qualia is simply having sensory experiences, if he attributes visual sensory experiences to blindsighters, he thereby also attributes them visual qualia. But then, he cannot consistently maintain that what blindsighters lack is visual experience. If one wants to preserve the consistency of Dretske's position, one possible move would be to argue that the visual sensory representations present in blindsighters are representations in the cognitive system but not for the cognitive system. But one realizes that this move is in fact blocked, when one considers that the condition for a sensory representation to be a representation for a system is that the system be capable of exploiting it for the construction of conceptual representation and the regulation of behavior. Now, in the case of blindsight, this is precisely in order to account for the presence in the patients of conceptual representations playing a role in the control of behavior, that we had to postulate sensory representations. These representations are thus representations for the system and, according to Dretske's theory, this condition is sufficient for the system to be conscious 1 of them. Thus, holding that the impairment suffered by blindsighters is an impairment in consciousness 1 leads to contradictions in Dretske's representational theory of the mental.

One way for Dretske to avoid those contradictions would be to stop regarding blindsight as a problem concerning consciousness 1 and to consider it rather as a problem concerning introspective access to visual qualia and thus as a deficit in consciousness2. Using Shoemaker's terminology, one could say that what characterizes blindsighters is that in the visual modality they have only quasi-qualia. Recall, however, that there would remain this difference between Dretske and Shoemaker that for Dretske qualia and quasi-qualia can be defined in terms of sensory representational properties, whereas for Shoemaker qualitative properties are distinct from intentional properties. We have seen that Dretske was defining introspective consciousness in terms of metarepresentational properties. Blindsighters would then suffer from a metarepresentational deficit vis-à-vis their visual experience. The trouble with this explanation is that it invites the conclusion that all beings lacking metarepresentational capacities or having yet to develop those capacities would be in the same position vis-à-vis their experiences as the blindsighter vis-à-vis his visual experiences.

To put it bluntly, Dretske seems to be confronted with an unpleasant dilemma. $\mathrm{He}$ must choose between (1) putting in the same category animals, young children and blindsighters, by attributing them the same phenomenology or rather lack of it, or (2) if 
he wants blindsight to remain a special case, different from the case of animals and young infants, to make his theory self-contradictory. Let us note in passing, that, at first sight at least, Shoemaker seems to be in a better position. By refusing to identify phenomenal properties to intentional properties, he gives himself more room to maneuver. He can, for instance, help himself with a distinction between a conscious access to the phenomenal properties of representations and a conscious access to their intentional properties and, hence, claim that what characterizes blindsight is lack of conscious access to the phenomenal properties of representations but not to their intentional properties. He could also argue that since phenomenal properties are not representational properties, it is not, strictly speaking, necessary to have metarepresentational capacities to be conscious of them, and this would allow him to attribute to young children and to some animal species at least, real qualia and not merely quasi-qualia. However, my aim here is not to assess the value of Shoemaker's theory. It may have to face other difficulties. Anyway, it does not seem to be directly susceptible to the same criticisms as Dretske's theory.

\section{III}

In the second half of this paper, I will be concerned with what the conditions for the identity or difference between qualitative experiences are and with how they they can be spelled out in the framework of Dretske's representational theory. I shall try to highlight a number of difficulties that arise in this setting. The present section discusses problems regarding the possibility of qualia inversions.

Dretske contends that the qualitative character of perceptual experience is not functionally definable. What he means is that it is not definable in terms of an identity or a difference in discriminatory behavior. His objection to the functionalist approach to qualia is the well-known objection that such an approach cannot account for possibilities such as the inversion of the color spectrum. Dretske's own example of qualia inversion involves not colors but tastes. Two individuals could be equally incapable of discriminating wines and thus each have all red wines taste the same to him. It is nevertheless possible that all red wines would taste to one the way fine Burgundies taste to a connoisseur, and that all red wines would taste to the other the way a cheap Chianti tastes to a Connoisseur.

According to Dretske, a representational theory of qualitative experience can account for such possibilities. Recall that, in outline, Dretske's representational theory identifies qualia with phenomenal properties, i.e. the properties that an object is sensuously (and systemically) represented as having. In order to account for possibilities such as the possibility of color inversion, without postulating that they constitute a brute, irreducible fact, one needs to be able to characterize objectively the differences between qualitative experiences even when they do not give rise to publicly observable differences in discriminatory behavior. In other words, one must be able to maintain a distinction between discriminated properties and sensuously represented properties. There is in Dretske's theory of representations a distinction that may help us in this task. This is the distinction between indicator capacities and indicator functions. The notion of an indicator function plays a crucial role in Dretske's account of misrepresentation, considered as the result of a discrepancy between what a token of a state actually indicates and what it is its function to indicate. Now, the problem with a purely functional definition of qualia is, Dretske claims, that it makes such a discrepancy impossible since sensory qualities are defined in terms of what can actually be discriminated. By constrast, if, as he suggests, qualia are defined in terms of representational properties, it remains possible to draw a distinction between what a sensory state actually discriminates and what it is its function to discriminate. 
A theory that identifies qualia with representational properties and that defines those properties in turn in terms of their indicator functions presents in Dretske's opinion two important advantages. First, insofar as what a system actually discriminates is not necessarily a direct reflection of what its states have as their function to discriminate, qualia defined in terms of those functions can have a subjective or private character: the differences between qualia do not necessarily express themselves in the behavior of the system in which they exist. Second, the nature of qualia is nevertheless objectively determinable : insofar as qualia are biologically inherited systemic representations, to determine the nature of a quale is to determine the biological function of states of this type. The nature of qualia is thus as objectively determinable as are the functions of bodily organs.

In Explaining Behavior (1988), Dretske offers a detailled discussion of the conditions necessary for attributing indicator functions to the states of a system. He distinguishes between two types of natural processes that may explain how the states of a system can acquire a indicator function: natural selection and individual learning. It is natural selection that is assumed to be responsible for the existence of sensory representational properties. According to Dretske's proposed story, states of a certain type $E$ in an organism have it as their biological function to indicate the presence of $F$ s, iff: (1) in the ancestors of this organism, states of this type were indicators of (inter alia) the presence of $F \mathrm{~s}$ in the conditions then prevalent in their environment, (2) states of type $E$ contributed in these ancestors to the causation of a behavior $B$ whose success was (partly) dependent on the presence of $F$ s and (3) the reason why states of this type have been retained by natural selection is that they indicated $F$ and contributed to the causation of $B$. In such a framework, to define a quale is to identify its indicator function. This in turn requires that the correct selectionist explanation accounting for the presence of this type of states in members of a given species be found.

We can now present in some more detail the strategy Dretske wants to use in order to account for the possibility that organisms whose behaviors are indistinguishable may nevertheless have different qualitative experiences (or equally, although the case is less often considered, that individuals whose discriminatory behaviors are different nevertheless have identical qualitative experiences). The strategy consists in exploiting the possibility that there exists a discrepancy or departure between what a state belonging to a certain type (or even a certain state type) has the function of indicating and what it actually indicates. The discrepancy can have causes that are either external to the organism or internal to it. It can be the result of a change in the environment: the background conditions upon which the indicator relations are contingent can have undergone changes and not correspond anymore today to the background conditions that played a role in the selectionist explanation. This discrepancy can also be due to dysfunctions in the organism itself, either transitory dysfunctions (tiredness, illness, etc.) or more or less permanent dysfunctions (genetic defects, breakdowns due to ageing, etc.). In the case of qualia, the discrepancy can be all the more radical since we are dealing with innate systemic representations, whose indicator functions depend on natural selection. The time-scale that goes together with explanations of that kind is such that it is conceivable that in a given individual or even in one or several generations of individuals in a given species, a systematic discrepancy exists between the indicator functions of certain states and what those states do in fact indicate.

If we go back to Dretske oenological example, we might explain the difference in qualitative experience between Jean who enjoys Burgundy qualia and Giovanni who has to be content with Chianti qualia in the following way. Human beings are normally endowed with a system of gustatory (and olfactory) sensory state types. States of each type have it as their function to represent a different quality of taste. As members of the 
human species, Jean and Giovanni both have states with those functions. Both of them, however, suffer malfunctions of their system of sensory gustatory representations, but they are different malfunctions. In the case of Jean, the diagnosis is the following: Jean has lost the ability to realize sensory states corresponding to representations of wine tastes other than Burgundy and stimuli that in normal subjects cause such states cause in Jean representational states corresponding to the taste of Burgundy. Mutatis mutandis, Giovanni has lost the capacity to realize sensory states corresponding to representations of wine tastes other than the taste of Chianti and stimuli that in normal subjects cause such states cause in Giovanni representational states corresponding to the taste of Chianti.

Admittedly, the explanation Dretske gives of his example could be correct. However, one can complain that it does not have the generality required to account for all the possible cases of differences in qualitative experiences that are not reflected in behavioral differences. I tend to think that the reason why his explanation of the wine example seems at first sight acceptable is that there is an important difference between that example and the problem of inverted spectrum in its traditional guise. Certainly, by hypothesis, we have in both cases qualitative differences not accompanied by behavioral differences. For instance, the fact that Jean enjoys Burgundy qualia each time he drinks wine does not make him more adept to wine-drinking than poor Giovanni fated to cheap Chianti taste. However, the wine example supposes that in the case of both Jean and Giovanni there is a systematic discrepancy between what their sensory states actually indicate and what they have as their function to indicate. By contrast, in the original example of the inverted color spectrum, it may be supposed that one of the two protagonists has sensory states that actually indicate what it is their function to indicate.

The example of the inverted color spectrum raises other problems, as noted by Dretske who devised his wine example in order to avoid those. A frequently mentioned objection to the inverted spectrum is that it would necessarily disturb the organization of an highly structured quality space and thus would have consequences detectable in behavior. Insofar as Dretske grants the possibility in principle of a spectrum inversion and in order not to get lost in subsidiary discussions concerning the plausibility of such or such particular example, I will examine the possibility in purely theoretical terms. The situation I will consider is that of two individuals whose visual experiences are minimally complex, and whose corresponding quality spaces are minimally structured with only two possible values.

The situation of our two individuals, Tictac and Tactic, is the following: (1) they both make the same discriminations between two classes of stimuli on the basis of their quality space, (2) they have inverted qualitative experience, and (3) Tictac qualitative experiences represent accurately what they are supposed to represent. Tictac distinguishes the stimuli presented to him in two classes, the $F$ s and the $G$ s. The $F \mathrm{~s}$ cause in Tictac tokens of a state type $M$ corresponding to qualitative experience of type tic and having the function of indicating the presence of $F \mathrm{~s}$. The $G$ s cause in Tictac tokens of a state type $N$ corresponding to qualitative experience of type tac and having the function of indicating the presence of $G$ s. We have, let us suppose, an evolutionary story that explains why Tictac's $M$ states have it as their function to represent $F$ s and why its $N$ states have it as their function to represent $G$ s. By hypothesis, Tactic does the exact same discriminations as Tictac, but in his case $F$ s cause states of type $N^{*}$ and qualitative experiences of type $t a c$, whereas $G$ s cause states of type $M^{*}$ and qualitative experiences of type tic. 9

\footnotetext{
${ }^{9}$ I speak of Tactic's $\mathrm{M}^{*}$ and $\mathrm{N}^{*}$ states rather than simply inverting $\mathrm{M}$ and $\mathrm{N}$ states in order to avoid a possible causal objection. According to the objection, it would be a violation of the principle of the
} 
How can we explain Tactic's situation? A possible explanation, along the lines of Dretske's account, would be to claim, first, that in Tactic's ancestors $M^{*}$ states have (just as $M$ states in Tictac's ancestors) been selected because they indicated the presence of Fs, and similarly for $N^{*}$ and $G \mathrm{~s}$, but that, second, in Tactic a genetic defect was responsible for a the connections getting crossed. But an alternative explanation would consist in claiming that in Tactic's ancestors,$M^{*}$ states were selected because they indicated the presence of $G$ s and, similarly for $N^{*}$ and $F$ s. In other words, according to this alternative story, it was benefical for both Tictac's and Tactic's ancestors to discriminate between the $F \mathrm{~s}$ and the $G \mathrm{~s}$, but the ones achieved the discrimination by associating $M$ states to $F \mathrm{~s}$ and $N$ states to $G$ s, the others by associating $N^{*}$ to $F$ s and $M^{*}$ to $G$ s.

What reasons could one put forward in favor of one story over the other? Dretske could claim that the situation as described in the second explanation is impossible since if the function of $M$ states in Tictac's ancestors had been to indicate the presence of $F$ s, then these states would be qualitatively identical to the $N^{*}$ states of Tactic and his ancestors, which contradicts our initial hypothesis. But such a rejoinder seems to beg the question in favor of a representational theory of qualia. Actually, to be honest, one should admit that the two competing explanations rest on incompatible assumptions and thus that each is begging the question in its own way. However, if the Tictac vs. Tactic case is a correct illustration of what philosophers usually mean when they consider the possibility of qualia inversion and if it is acknowledged that such a situation is theoretically possible, it is clear that Dretske must either admit that his theory denies such a possibility (the only possible cases of inversion being the weaker cases illustrated by the wine example), or, if he grants the possibility of strong qualia inversion, concede that his theory does not account for it.

Dretske (1995: 72) contends that, according to the representational theory of experience he advocates, the qualitative character of the experience is not functionally definable but is nevertheless physically definable. I am afraid that that his statement is somewhat misleading. It would be more accurate to say that according to his theory, qualitative experience is not functionally definable in the descriptive sense of a functional definition - the way a thing functions - which correspond to the use classical functionalists make of the term, but that it is functionally definable in the teleological sense of function - where function takes a normative dimension. Thus, the qualitative character of experience is physically definable only in the sense in which a biological function is physically definable. Quite surely, 'physically definable' should not be taken here in the strong sense of a physicalist reduction. For Dretske's suggestion that qualitative experience be defined in teleofunctional terms to answer the problem of qualia inversion, it would have to be supplemented by the further assumption that there can be no situations where qualitative differences occur between states indistinguishable

nomological character of causation to assume that, whereas Tictac and Tactic have both $\mathrm{M}$ states and $\mathrm{N}$ states, the Fs cause in one $\mathrm{M}$ states and in the other $\mathrm{N}$ states. Let us note, however, that the force of the objection depends, on the one hand, on what conception one holds of physical causality and, on the other hand, on the further stipulation that that there are no other aspects of the cognitive organization of Tictac or Tactic that might account for such a difference in the effects produced by the same cause. Besides, in order to forestall another objection, let us note that the situation described, where different states types $-\mathrm{M}$ and $\mathrm{N}$ for Tictac and $\mathrm{M}^{*}$ and $\mathrm{N}^{*}$ for Tactic — correspond to the values of the quality space, is perfectly compatible with Dretske's representational theory, since the theory holds that the indicator function of a type state and hence its qualitative aspects depend on relational properties of tokens of the type and not on their intrinsic properties. Thus, the issue is not whether states belonging to the same physical (or neurological) type can have different qualitative properties, but whether states belonging to the same representational type can have different qualitative properties. 
in terms of their teleofunctional characterisation. But Dretske offers no independent argument in favor of that assumption.

Now, its seems it is precisely intuitions concerning the plausibility of such situations that induce us to accept the theoretical possibility of qualia inversions. The idea behind those intuitions is that what matters is that organisms be capable of making the discriminations that are important for their survival, not that that they make those discriminations in such or such a way. If I am right to think that this is the main motivation in favor of the possibility of qualia inversion, then Dretske's theory does not solve the problem. It leaves no room for a distinction between what is discriminated and how discriminations are made, or, to put it more precisely, between what it is that the sensory states of an organism are supposed to discriminate (their indicator functions) and how they achieve their function. But his theory does no show either that our intuitions concerning the possibility of such a distinction are misguided.

\section{IV}

In this last section, I would like to examine another consequence of Dretske's theory. It concerns the qualitative differences between experiences in the different sensory modalities. It follows from his theory that the qualitative differences between experiences in different modalities (for instance, feeling vs. seeing) are never ascribable to the difference in the modalities by itself, but are always related either to differences in discriminatory powers or to differences in the conceptual exploitation of the information obtained. This consequence is unfortunate insofar as it forbids Dretske from availing himself of an important justification for the existence of qualia.

Dretske (1995: 93-95) offers a brief discussion of "what it is like to be an X". He points out that in order to know what it is like for a creature to have a qualitative experience of a given type, one needs to determine what it is that this qualitative experience represents. But he also claims that to know what it is like to be this creature, one has to know all the properties that the creature senses. Thus, for Dretske, what it is like to be such or such a creature is the total sum of all the properties it can experience. In other words, for there to be a difference between what it is like to be an $A$ and what it is like to be a $B$, it is both necessary and sufficient that there be at least one property that one of the two creatures but not the other is capable of sensuously representing.

For Dretske, the qualitative differences between experiences in different modalities are explained by the fact that we do not experience the exact same set of properties in the different modalities. To take his example, although an experience of movement can be either visual or tactile (or kinaesthetic), visual and tactile experiences are different, because when one visually experiences the movement of an object, one also experiences the object's shape, color, size, direction of movement and a host of other properties, whereas when one has a tactile experience of movement, different properties are simultaneously experienced. Even when the two sets of properties partially overlap, there remains a residue of unshared properties that give each modality its specific qualitative character.

From that account of the qualitative differences between modalities, it follows that if there where two creatures, who despite being equipped with different sensory modalities, would represent through those modalities the exact same set of properties, they would as a result have qualitatively identical experiences (in the same situations). Similarly, it follows from the theory that an individual who would represent the same set of properties via two different modalities could not feel qualitative differences between experiences in one or the other modality. By not considering the possibility that the qualitative differences between experiences in different sensory modalities could be more than just differences concerning the properties represented, Dretske runs counter 
to pretheoretical intuition. Of course, this in itself is no devastating objection. It seems to me, however, that there is an important link between (1) our ability to discriminate between different sensory modalities, (2) the reasons that can be invoked in favor of the accessibility to consciousness of qualia and (3) a fundamental property of our relation to objects in perception, that Husserl described as the Leibhaftigkeit or bodily presence of the object in perception and that distinguishes perception from other cognitive modes, such as imagination or memory. Dretske does not account for this property of bodily presence. His distinction between sensory and conceptual representations allows him to account for the difference between propositional attitudes such as beliefs, desires, intentions, etc., on the one hand, and attitudes the content of which is not propositional in form such as (non-epistemic) perception, but not for the differences between perception, imagination or 'imagistic memories 10

Let us first consider the link between a capacity to distinguish between sensory modalities and possible justifications of the accessibility to consciousness of sensory experience. I have already mentioned the suggestion that the main advantage of the accessibility to consciousness of sensory experience is to give us access to justifications we can then produce in favor of the beliefs we have formed on the basis of sensory information. But we can go further and suggest that, by knowing why we entertain those beliefs, what their grounds are, whether those grounds are sound or conjectural, we can voluntarily decide whether we need to check them further, whether we need to gather more information and when we must revise certain beliefs. In other words, accessibility to consciousness allows us to improve the reliability and relevance to the success of our actions of our perceptually formed beliefs. It is consistent with this hypothesis that the consciousness we have of our perceptual experience should include an awareness of the modality of these experiences. The process of justification of our perceptually based beliefs operates largely on-line, it is subject to immediate testing. If, for instance, I think that I may be seeing a friend on the other side of the street, before I accept this as a belief, I will proceed to further perceptual checking, observe with attention his gait, features, haircut, and so on. But there is no doubt that the process of verification will be quite different depending on whether I seem to see this friend in the street or to hear his voice in the next room. In the former case, I shall look carefully, in the latter I shall listen closely to check whether this is really his voice I am hearing.

Dretske would probably answer that in the example I have just given, I am informed of the sensory modality involved via the type of properties represented and that there is no need for further explanations. One can imagine, however, cases where the belief being checked concerns one or several properties that can in principle be sensuously represented in different modalities, but that in that instance were actually represented in only one of those. It seems implausible that the individual should proceed blindly (sorry for the pun!) in order to determine the modality involved and the type of check needed. But how do we distinguish between modalities if not merely on the basis of the properties represented? A possible answer would be to run directly counter to Dretske and to claim that our perceptual experience has a qualitative dimension that cannot be accounted for in representational terms. But this may be underestimating the resources available to a representational approach. I shall try instead to exploit the further resources such an approach may have at its disposal and see what we can do with them.

My suggestion is that a representational solution to the problem of Leibhaftigkeit and a representational solution to the problem of distinguishing between the modalities are

\footnotetext{
10 I use this term to refer to memories that involve imagistic representations as opposed to memories involving propositional content. This corresponds roughly to the distinction between memories linked to episodic memory and memories linked to generic memory.
} 
closely related. This does not mean that the two problems are in fact but one and the same, since for instance, if we were dealing with creatures equipped with a unique sensory modality, we obviously would not have to distinguish between modalities, but we would still have to face the problem of bodily presence. Leibhaftigkeit is, according to Husserl, a fundamental property of perception that refers to the very specific form the relation between the subject and the object of the attitude takes in this cognitive mode. Husserl gives the following description:

The object stands before us in perception as bodily present, as, to put it more precisely yet, actually present, as given in propria persona in the actual present. In imagination, the object does not stand before us in the mode of bodily presence (Leibhaftigkeit), of reality, of actual presence. Certainly, it stands before our eyes, but as an object that is not actually given now. It might be thought of as now present or as simultaneous to an actual present, but this presence is a presence in thought, not the presence that belongs to bodily presence, to the presence of perception. (1907, §4, pp. 14-15).

Bouveresse (1995: 52-54) quotes the preceding excerpt from Husserl and wonders whether the contrast pointed out by Husserl between a situation in which an object is perceived and a situation in which it is simply represented (including represented as given here and now) is not such as to cast doubt on the well-foundedness of representational approaches to perception.

I would like to suggest that, with respect to the problem of Leibhaftigkeit, a representational theory of perception may not be in a desperate position, provided that it takes into account the temporal dimension of perception and does not proceed to the reductive abstraction that makes perception something punctual and static. The idea that should be exploited is that perception has both a static simultaneous structure and a dynamic temporal structure, that there is a narrow link between the Leibhaftigikeit of the object in perception and the temporal dynamics of perception, and, finally, that the nature of our perceptual relation to the object gets displayed mainly in the flux of perception, that is in its temporal dynamics.

Very schematically then, what characterizes perception and accounts for its distinctive character is the fact that it exhibits a temporal organization the dynamics of which is under the dependence of both the object and the subject's activity of perceptual exploration. The object is given in propria persona insofar as the lawful organization of the perceptual sequence constitutes a test of its presence. Briefly put, the fact that in perception the object appears given in propria persona results from the conjunction of the three following conditions: (1) the temporal dynamics of the sequence of perceptual moments does not depend entirely on the perceiver, (2) what depends on the perceiver is correlated with his perceptual-motor exploration activity 11 , i. e. with an active perceptual exploration of the scene presented, and (3) what in this dynamics is not under the control of the perceiver nevertheless exhibits a lawful character. I contend that in the other cognitive modes, the three conditions are not simultaneously satisfied. In particular, those other modes display no systematic correlations with the motor activity of the subject. I can, for instance, close my eyes and imagine a cube, I can even imagine

\footnotetext{
${ }^{11}$ By perceptual-motor activity, I mean motor activity the purpose of which is to obtain perceptual information from the world. The effects of this activity on perception can have a greater or lesser strength. For instance, moving one's head usually has a marked effect on the flux of visual information, which is not the case with straightening one's back or flexing one's toes. Besides, a change in the informational flux can be a side effect of some motor activity aiming at different goal, or it can be the intended effect of motor activity. It the latter case, we have an instance of perceptualmotor exploration activity.
} 
myself turning around the cube, I can during this exercise move my head and my body in different ways, but, unless by a coincidence or because of my deliberately intenting it to be so, my movements will not be correlated with the sequences of images of the cube that I imagine myself to be turning around.

So, it seems that we might be able to account for the Leibhaftigkeit of the object in perception in the framework of a representational theory of perception, provided that we make use of a richer notion of representation. In other words, this seems to be possible, provided that, as a first condition, the notion of representation used covers both sensory representations taken in the static way in which Dretske considers them and sensory properties taken in a dynamical way. Let us note, that a dynamic sensory representation is not merely a temporal sequence of static representations, but that it is a representation of the relationships between the successive static representations. The order of complexity of dynamic representations is thus higher that of static sensory representations. This means that dynamic representations require more sophistated representational mechanisms that can extract relations between representational moments in a perceptual sequence. Although necessary, this condition is not yet sufficient. If the sketch I gave of an analysis of Leibhaftigkeit is correct, to enjoy Leibhaftigkeit, an organism must also be able to discriminate between those relations that depend on his activity and those that do not. Thus, it is necessary to allow for a further mechanism, the function of which will be to discriminate between those two types of relations by extracting correlations between the dynamical properties of perceptual experience and the motor activity of the organism. But one of the outcomes of such a discrimination will be to tell us which sensory modality is involved.

The object is given in propria persona, through those relations between perceptual moments the lawful character of which is not ascribable to the motor activities of the perceiver. But, simultaneously, what distinguishes between the different modalities is the type of correlations they exhibit between the dynamic properties of the perceptual sequence and the sensory-motor activity of the organism. In other words, what perceptual sequences it is possible or typical to experience, depends on constraints ensuing both from the nature of the object experienced and from the nature of the sensory modality involved. To put it roughly, each sensory modality has its own exploratory modes that impose constraints on the nature of possible or typical perceptual sequences in the modality. Hence, assuming that the exact same sensory properties can be represented in two different modalities, the resulting perceptual experiences might nevertheless have a different temporal dynamics. What it is like to sensuously represent an object in one modality could thus be different from what is is like to represent the same object in a different modality.

To sum up, I have attempted to bring into light certain difficulties or weaknesses in Dretske's theory of perceptual experience. However, not all the difficulties examined seem to me to have the same degreee of seriousness. I should like to close this paper with a brief assessment on their respective consequences for the prospect of a representational approach to perception. The first problem I discussed concerned the relation between qualia and consciousness and the use Dretske makes in his analysis of blindsight of the distinction between consciousness 1 , that does not require conceptual or metarepresentational capacities, and consciousness2, that requires by constrast metarepresentational capacities. It seems to me that this problem casts light on an important flaw in the organization of Dretske's theory, but not, however, that it poses an insuperable challenge to a representational approach to perceptual experience, provided such an approach operates with finer distinctions than the simple dichotomy between 
sensory and conceptual representations and that, at the same time, it acknowledges several levels of integration between representations and actions 12 Assuming that the brief sketch I gave of a possible explanation of the Leibhaftigkeit of perception and of our capacity to distinguish between modalities is correct, or, say, points approximately in the right direction, these two properties should not constitute fatal obstacles for a representational theory of perceptual experience. What a purely representational theory of perceptual experience seems unable to account for, however, is the possibility of qualia inversions, such as the inversion of the color spectrum. Dretske's theory does indeed explain some weaker forms of qualia inversions, as illustrated by his wine example, but he does not offer a comprehensive explanation of possible qualia inversions, that embraces fully fledged cases of inversion. In this respect, a representational theory displays no decisive advantage vis-à-vis a functional theory of qualia. Individual qualia are no more teleofunctionally or representationally definable than they are functionally definable. A major problem that remains unsolved and apparently insoluble in a purely representational framework is what one could call the problem of the qualitative multirealizability of representational contents.

\footnotetext{
12 Neuropsychologists working on blindsight insist on the existence of different types of representations corresponding to different levels or modes of processing of sensory information, for instance "where" representations (localization) versus "what" representations (object identification). They also emphasize the existence of different levels of integration between representations and actions or behaviors. For instance, certain dissociations seem to point to the existence of a system of "how" representations, responsible for a pragmatic processing of sensory information which directly links this information to certain motor behavior, without the mediation of "where" or "what" representations (Rossetti, Rode, \& Boisson, 1995). By contrast, other types of behaviors or actions operate in relation with more symbolic or more detached levels of representations (Jeannerod, 1994; McCarthy \& Warrington, 1990, Paillard, 1991; Ungerleider \& Mishkin, 1982). Furthermore, one may think that conscious perceptual experience is linked to detached or demodularized forms of representations (Karmiloff-Smith, 1992). In Darwinian terms, one may think it would be useless to be conscious of representations the consequences of which we could not influence because they automatically unfold anyway.
} 


\section{Bibliographie}

Armstrong, D. M., 1980, "What is consciousness", in The Nature of the Mind, Ithaca: Cornell University Press, pp. 55-67.

Bouveresse, J., 1995, Langage, perception et réalité, Vol. I, Paris: Éditions Jacqueline Chambon.

Dennett, D., 1988, "Quining Qualia”, in A. J. Marcel \& E. Bisiach (eds) Consciousness in Contemporary Science, Oxford: The Clarendon Press, pp. 42-77.

Dretske, F., 1988, Explaining Behaviour, Cambridge, Mass.: MIT Press.

Dretske, F., 1995, Naturalizing the Mind - The Jean Nicod Lectures - 1994 Paris: Editions du CNRS \& Cambridge, Mass.: MIT Press.

Hardin, C. L., 1986, Color for Philosophers, Indianapolis, IN: Hackett.

Husserl, E., 1907, Ding und Raum, Vorlesungen 1907, K.-H. Hahnengress \& S. Rapic (eds), Hamburg, Felix Meiner, 1991.

Jeannerod, M., 1994, "Object oriented action", in K. M. B. Bennett \& U. Castiello (eds) Insights into the Reach to Grasp Movement, Amsterdam, Elsevier, pp. 3-15.

Karmiloff-Smith, A., 1992,Beyond Modularity, Cambridge, Mass.: MIT Press.

Marcel, A. J., 1988, "Phenomenal experience and functionalism", in A. J. Marcel \& E. Bisiach (eds) Consciousness in Contemporary Science, Oxford: The Clarendon Press, pp. 121-158.

McCarthy, R. A. \& E. K. Warrington, 1990, Cognitive Neuropsychology, New-York: Academic Press.

Paillard, J., 1991, "Motor and representational framing of space", in J. Paillard (ed.) Brain and Space, Oxford: Oxford University Press.

Perner, J., 1991, Understanding the Representational Mind, Cambridge, Mass.: MIT Press.

Rosenthal, D., 1986, “Two concepts of consciousness", Philosophical Studies, 49, pp. 329-59.

Rossetti, Y., Rode, G. \& Boisson, D., 1995, "Implicit processing of somaesthetic information: a dissociation between where and how?", NeuroReport, 6, 506-510.

Shoemaker, S. 1991, "Qualia and Consciousness", Mind, C, 4, pp. 507-524.

Ungerleider, L. G. \& M. Mishkin, 1982, “Two cortical visual systems”, in D. J. Ingle, M. A. Goodale \& R. J. W. Mansfield (eds), Analysis of visual behaviour, Cambridge, Mass.: MIT Press.

van Gulick, R., 1993, "What difference does consciousness make?", Philosophical Topics, 17: 211-230.

Weizkrantz, L., 1986, Blindsight: a case study and implications, Oxford: Oxford University press.

Weizkrantz, L., 1988, "Some contributions of neuropsychology of vision and memory to consciousness", in A. J. Marcel \& E. Bisiach (eds) Consciousness in Contemporary Science, Oxford: The Clarendon Press, pp. 183-199.

Young, A. W. \& E. H. F. De Haan, 1993, "Impairments of visual awareness", in M. Davies \& G. W. Humphreys, (eds) Consciousness, Oxford: Basil Blackwell, pp. 5873. 